\title{
PENGARUH MODEL PEMBELAJARAN KOOPERATIF TIPE GROUP INVESTIGATION TERHADAP HASIL BELAJAR FISIKA SISWA SMAN 9 MEDAN T.P. 2015/2016
}

\author{
Putri Sion Rumahorbo dan Jonny Haratua Panggabean \\ Jurusan Fisika FMIPA Universitas Negeri Medan \\ putrifis12@gmail.com
}

\begin{abstract}
ABSTRAK
Penelitian ini bertujuan untuk mengetahui pengaruh model pembelajaran kooperatif tipe group investigation (GI) terhadap hasil belajar siswa pada materi pokok suhu dan kalor di kelas X semester II SMAN 9 Medan T.P. 2015/2016. Jenis penelitian ini adalah penelitian quasi eksperimen dengan menggunakan two group pretest-posttest design. Pengambilan sampel berdasarkan teknik cluster random sampling dari populasi seluruh siswa kelas X SMAN 9 Medan. Sampel penelitian terdiri dari dua kelas, yaitu kelompok eksperimen yang menerapkan model pembelajaran kooperatif tipe GI dan kelompok kontrol yang menerapkan pembelajaran konvensional yang masing-masing berjumlah 35 orang. Instrumen yang digunakan adalah tes hasil belajar siswa dalam bentuk pilihan berganda sebanyak 20 soal. Hasil penelitian menunjukkan bahwa penggunaan model pembelajaran kooperatif tipe GI pada materi pokok suhu dan kalor di kelas X semester II SMAN 9 Medan T.P. 2015/2016 secara signifikan lebih berpengaruh dalam meningkatkan hasil belajar siswa.
\end{abstract}

Kata kunci: model pembelajaran kooperatif tipe GI, hasil belajar, suhu dan kalor

\begin{abstract}
The purpose of this research was to find out the effect of cooperative learning model type of group investigation(GI) on student's learning outcomes in temperature and heat subject matter in class X even semester SMAN 9 Medan learning year 2015/2016. This research is a quasi experiment using two group pretest-posttest design. The sampling based on random cluster sampling technique from all student population on class X SMAN 9 Medan. The research sample was consist of two classes that was experiment class that using cooperative learning model type of GI and control class that using conventional learning, and each classes consist of 35 students . The instrument used was a test of student learning outcomes in the form of multiple choices as much as 20 questions. The result showed that an application of cooperative learning model type of GI in temperature and heat subject matter in class X even semester SMAN 9 Medan learning year 2015/2016, significantly more effective to improve student's learning outcomes.
\end{abstract}

Keywords: cooperative learning model type GI, learning outcomes, temperature and heat 


\section{PENDAHULUAN}

Pendidikan merupakan salah satu faktor yang sangat penting dalam kehidupan manusia, karena dengan pendidikan, manusia dapat meningkatkan kualitas sumber daya manusia (SDM) yang akan mempengaruhi peningkatan berbagai bidang di dalam kehidupan seperti bidang ekonomi, politik, sosial, dan budaya. Ditinjau dari bentuk kegiatannya, pendidikan mempunyai ruang lingkup yang terentang dari bentuk-bentuk informal yang tidak direncanakan sampai dengan bentukbentuk pendidikan formal yang terprogram. Contoh pendidikan formal adalah sekolah. Sekolah sebagai hasil rekayasa manusia diciptakan untuk menyelenggarakan pendidikan (Mudyahardjo, 2010). Salah satu bentuk penyelenggaraan pendidikan formal yaitu Sekolah Menengah Atas (SMA). Salah satu bidang studi di tingkat SMA yaitu mata pelajaran fisika, yang merupakan pelajaran yang lebih menekankan konsep. Penekanan konsep akan membuat siswa memperoleh pemahaman yang benar tentang materi fisika dan memahami penerapannya dalam kehidupan seharihari. Pemahaman konsep fisika dengan baik belum dapat dianggap tuntas jika siswa hanya mampu menghafal rumus dan menghitung soal-soal fisika saja.

Pembelajaran di Kurikulum 2013 menerapkan pendekatan yang berpusat pada siswa, sehingga siswa dituntut untuk lebih aktif menemukan konsep dari pelajaran fisika. Hasil pembagian angket kepada siswa kelas X SMAN 9 Medan, mereka menyatakan kegiatan pembelajaran fisika di kelas berlangsung dengan mencatat dan mengerjakan soal-soal yang artinya siswa hanya menerima pembelajaran bukan menemukan sendiri. Masalahnya, apabila guru yang lebih aktif dibandingkan siswa atau apabila proses pembelajaran masih berpusat pada guru akan menyebabkan siswa tidak aktif untuk menemukan sendiri konsep dari pembelajaran, siswa hanya akan sekedar mendengarkan dan mencatat penjelasan guru dan selanjutnya mengerjakan soal.

Keberhasilan pengajaran fisika tidak terlepas dari peran guru dalam mengelola perangkat-perangkat pembelajaran supaya tujuan pembelajaran tercapai yang ditandai dengan meningkatnya hasil belajar siswa. Berdasarkan hal itu pembelajaran yang diterapkan perlu diperbaiki untuk mengatasi permasalahan-permasalahan yang telah terjadi dalam pengajaran di kelas. Salah satu upaya untuk mengatasi permasalahan di atas dapat dengan menggunakan model pembelajaran yang efektif, yang dapat meningkatkan keaktifan siswa dalam kegiatan pembelajaran untuk menemukan sendiri konsep fisika, yang berpusat pada siswa sesuai dengan Kurikulum 2013, dan yang dapat meningkatkan pengetahuan konsep siswa, yang dengan sendirinya diharapkan dapat meningkatkan hasil belajar siswa pada pengetahuan konsep fisika.

Model pembelajaran yang menurut penulis efektif yaitu model pembelajaran kooperatif dengan tipe GI. Model pembelajaran kooperatif tipe GI tepat untuk mengatasi masalah di atas karena tujuan kognitif atau hasil dari GI adalah pengetahuan konseptual akademis (Arends, 2008). Model pembelajaran ini menekankan penyelidikan dalam mencapai tujuan pembelajaran, sehingga siswa bukan hanya mendengar penjelasan, mencatat 
dan mengerjakan soal, tetapi siswa akan lebih aktif dengan melakukan penyelidikan bersama dengan teman sekelompoknya untuk mencapai tujuan dari topik yang dibahas. Slavin (2005), mendeskripsikan enam tahap dalam model pembelajaran kooperatif tipe GI yaitu: mengidentifikasikan topik dan mengatur siswa ke dalam kelompok, merencanakan tugas yang akan dipelajari, melaksanakan investigasi, menyiapkan laporan akhir, mempresentasikan laporan akhir, dan melakukan evaluasi. Peserta didik memperoleh informasi, menganalisis informasi, memberikan ide, dan secara bersama menyelesaikan masalah atau menghasilkan produk untuk disajikan di depan kelas (Sani, 2014). Melalui penerapan model pembelajaran kooperatif tipe GI diharapkan hasil belajar siswa pada pengetahuan konsep fisikanya akan meningkat.

Penelitian terkait model pembelajaran kooperatif tipe GI ini sudah pernah diteliti sebelumnya. Peneliti sebelumnya yaitu Sakinah dan Purwanto (2014), Simanjuntak dan Simanjuntak (2014), Harahap dan Turnip (2014), dan Yasemin, et al., (2010). Berdasarkan hasil penelitian mereka didapatkan bahwa melalui model pembelajaran kooperatif tipe GI hasil belajar fisika siswa meningkat, dan dibandingkan dengan pembelajaran konvensional, GI adalah lebih efektif untuk meningkatkan prestasi akademik siswa.

Berdasarkan uraian di atas, dilaksanakan penelitian dengan tujuan untuk mengetahui pengaruh model pembelajaran kooperatif tipe GI terhadap hasil belajar siswa pada materi pokok suhu dan kalor di kelas X semester II SMAN 9 Medan T.P. 2015/2016.

\section{METODE PENELITIAN}

Populasi dalam penelitian ini adalah seluruh siswa kelas $\mathrm{X}$ semester II SMAN 9 Medan. Sampel dalam penelitian ini terdiri dari dua kelas yang dipilih secara acak dengan teknik cluster random sampling yang melibatkan dua kelas yang diberi perlakuan berbeda. Kelas eksperimen dengan menggunakan model pembelajaran kooperatif tipe GI sedangkan di kelas kontrol menggunakan pembelajaran konvesional.

Penelitian ini termasuk jenis penelitian quasi eksperimen dan desain penelitian yang digunakan adalah two group pretest-postest design. Rancangan penelitian ini ditunjukkan pada Tabel 1 .

Tabel 1. Pretest-Posttest Design

\begin{tabular}{|l|c|c|c|}
\hline Kelas & Pretest & Perlakuan & Posttest \\
\hline Eksperimen & $\mathrm{O}$ & $\mathrm{X}$ & $\mathrm{O}$ \\
\hline Kontrol & $\mathrm{O}$ & $\mathrm{Y}$ & $\mathrm{O}$ \\
\hline
\end{tabular}

Keterangan:

$\mathrm{X}=$ model pembelajaran kooperatif tipe GI

$\mathrm{Y}=$ pembelajaran konvensional

$\mathrm{O}=$ instrumen/tes hasil belajar

Uji Lilliefors digunakan untuk mengetahui data populasi sampelsampel yang secara teoritik sampai tak terhingga, berdistribusi normal. Uji homogenitas digunakan untuk mengetahui apakah data populasi sampel-sampel yang secara teoritik sampai tak terhingga berasal dari populasi yang homogen. Uji homogenitas menggunakan uji kesamaan varians.

Pengujian hipotesis digunakan uji t dengan rumus (Sudjana, 2005): 


$$
t=\frac{\bar{X}_{1}-\bar{X}_{2}}{s \sqrt{\frac{1}{n_{1}}+\frac{1}{n_{2}}}}
$$

\section{HASIL DAN PEMBAHASAN Hasil Penelitian}

Penelitian ini melibatkan dua kelas yang diberi model pembelajaran yang berbeda yaitu pada kelas eksperimen menggunakan model pembelajaran kooperatif tipe GI dan pada kelas kontrol menggunakan pembelajaran konvensional. Sebelum ke dua kelas diberi perlakuan kedua kelas terlebih dahulu diberikan pretes yang bertujuan untuk mengetahui kemampuan awal siswa.

Berdasarkan hasil pretes yang diperoleh, nilai rata-rata pretes kelas eksperimen 37,00 dan nilai pretes kontrol 37,71. Selanjutnya kelas eksperimen dan kelas kontrol diberikan perlakuan yang berbeda. Kelas eksperimen menggunakan model pembelajaran kooperatif tipe GI dan pada kelas kontrol menggunakan pembelajaran konvensional. Setelah ke dua kelas diberi perlakuan, masingmasing kelas diberi postes untuk melihat adanya pengaruh akibat diberikan perlakuan pembelajaran yang berbeda. Berdasarkan data postes ke dua kelas diperoleh nilai rata-rata untuk kelas eksperimen sebesar 72,43 dan nilai rata-rata postes kelas kontrol sebesar 60,57.

Berdasarkan hasil uji normalitas dengan menggunakan uji Lilliefors untuk populasi sampel-sampel penelitian diperoleh bahwa nilai pretes berdistribusi secara normal. Demikian juga pada data postes, nilai yang diperoleh menurut hasil uji Lilliefors, berdistribusi normal. Kesimpulan dari uji normalitas bahwa sampel yang ditentukan dalam penelitian ini telah berdistribusi normal.

Pengujian homogenitas data pretes dan data postes pada kelas eksperimen dan kelas kontrol dilakukan dengan uji kesamaan dua varians untuk mengetahui apakah kelompok sampel berasal dari populasi yang homogen atau tidak. Hasil uji homogenitas data yang diperoleh menunjukkan bahwa data pretes dan postes untuk kelompok sampel yang dipilih homogen.

Data ke dua sampel dinyatakan normal dan homogen sehingga layak dilakukan uji hipotesis.

Tabel 2. Hasil Uji Hipotesis Data Pretes dan Postes

\begin{tabular}{|c|l|c|c|c|}
\hline Data & \multicolumn{1}{|c|}{ Kelas } & Rata-rata & $\mathbf{t}_{\text {hitung }}$ & $\mathbf{t}_{\text {tabel }}$ \\
\hline \multirow{2}{*}{ Pretes } & Eksperimen & 37,00 & & \multirow{2}{*}{$-0,321$} \\
\cline { 2 - 5 } & Kontrol & 37,797 & & \\
\hline \multirow{2}{*}{ Postes } & Eksperimen & 72,43 & \multirow{2}{*}{3,539} & 1,669 \\
\cline { 2 - 5 } & Kontrol & 60,57 & & \\
\hline
\end{tabular}

Berdasarkan Tabel 2, data pretes diperoleh bahwa kemampuan awal siswa pada kelas eksperimen sama dengan kemampuan awal siswa pada kelas kontrol. Data postes yang diperoleh menunjukkan bahwa hasil belajar siswa pada kelas eksperimen lebih besar dari kelas kontrol, sehingga dapat disimpulkan bahwa ada pengaruh yang signifikan akibat penerapan model pembelajaran kooperatif tipe GI terhadap hasil belajar siswa pada materi pokok suhu dan kalor di kelas X semester II SMAN 9 Medan T.P. 2015/2016.

\section{Pembahasan}

Perbedaan hasil belajar siswa pada kedua kelas ini diuji dengan uji beda, dari hasil uji $t$ menyatakan adanya perbedaan yang signifikan 
antara hasil belajar siswa yang diajarkan dengan model pembelajaran kooperatif tipe GI dengan yang diajarkan dengan pembelajaran konvensional. Perbedaan hasil belajar disebabkan oleh kelebihan model pembelajaran kooperatif tipe GI yang melibatkan siswa mulai dari awal pembelajaran hingga akhir pembelajaran dengan mengikuti setiap fase pembelajarannya. Fase pertama yaitu pemilihan topik, siswa terlibat dalam memilih sub topik yang akan mereka selidiki, sub topik yang dipilih siswa bebas dari pemikiran yang didapatkan siswa tetapi harus sesuai dengan topik pembelajaran hari itu. Fase ke dua yaitu perencanaan kooperatif, siswa juga dilibatkan dengan membagi tugas setiap anggotanya untuk menyelidiki sub topik-sub topik yang mereka pilih. Fase ke tiga yaitu implementasi, semua siswa dilibatkan dalam mengerjakan setiap tugasnya, siswa yang mengerjakan topik pertama atau praktikum, melakukan penyelidikan dengan mengikuti langkah-langkah yang terdapat dalam lembar kerja siswa, sedangkan bagi siswa yang mendapatkan tugas pada sub topik dua melakukan penyelidikan dengan meninjau dari berbagai literatur berupa buku pelajaran atau dari internet. Fase ke empat yaitu analisis dan sintesis, setiap siswa terlibat dalam kelompoknya untuk menyatukan setiap hasil penyelidikan mereka, yang kemudian dirangkum untuk dipersiapkan untuk dipresentasikan di depan kelas. Fase ke lima yaitu presentasi hasil akhir, dua kelompok akan menyajikan presentasi yang dipilih secara berurut dari nomor kelompok dan kelompok yang tidak presentasi terlibat dengan bertanya dan menanggapi hasil presentasi. Fase ke enam yaitu evaluasi, siswa terlibat dalam menyimpulkan materi pembelajaran dan siswa yang presentasi akan mendapatkan penghargaan dari guru dan teman sekelas atas hasil presentasi mereka berupa applause kemudian siswa diberikan evaluasi mandiri sebanyak empat soal terkait dengan topik pembelajaran hari itu.

Adanya perbedaan hasil belajar disebabkan oleh kelebihan model pembelajaran kooperatif tipe GI yang tidak mengharuskan siswa menghafal fakta tetapi sebuah model yang membimbing para siswa untuk menemukan sendiri konsep dari fisika (Simanjuntak dan Simanjuntak, 2014). Model pembelajaran kooperatif tipe GI lebih berpengaruh karena melibatkan siswa secara aktif sejak perencanaan pembelajaran, baik dalam menentukan topik yang akan dibahas maupun cara untuk mempelajarinya melalui investigasi kelompok (Sakinah dan Purwanto, 2014). Model pembelajaran kooperatif tipe GI juga lebih berpengaruh dibandingkan dengan pembelajaran konvensional karena semua anggota kelompok wajib mendapatkan tugas, hal ini menyebabkan setiap anggota kelompok aktif (Harahap dan Turnip, 2014). Dibandingkan dengan pembelajaran tradisional (konvensional), model pembelajaran kooperatif tipe GI lebih berpengaruh dalam meningkatkan prestasi akademik siswa, karena siswa lebih berkontribusi dalam mengajukan pendapat mereka dan bekerjasama dengan siswa lainnya (Yasemin, et al., 2010). Sharan and Sharan (1990), menyatakan model pembelajaran kooperatif tipe GI sangat efektif karena model ini memberikan siswa 
kesempatan yang lebih banyak untuk mengontrol apa yang mereka pelajari.

Walaupun model pembelajaran kooperatif tipe GI mampu meningkatkan hasil belajar siswa tetapi dalam pelaksanaannya terdapat juga kendala-kendala saat menerapkan setiap fase. Kendala tersebut yaitu pada fase pertama, siswa belum terlibat dalam mengajukan sub topik pilihan, sehingga pada pertemuan pertama sub topik pilihan siswa bagi keseluruhan kelompok masih ditentukan oleh guru. Adapun yang peneliti lakukan untuk menyelesaikannya, membimbing dan mengarahkan siswa dalam pemilihan sub topik sehingga siswa mampu memilih sub topik pilihan mereka dan sub topik yang dipilih siswa tidak menyimpang dari materi pembelajaran.

Kendala berikutnya yaitu pada pertemuan pertama siswa belum memahami cara menjalankan prosedur pembelajaran dan pembagian tugas untuk siswa. Adapun yang peneliti lakukan untuk menyelesaikannya yaitu menjelaskan kepada siswa prosedur pembelajaran dan cara membagi tugas dari setiap anggota kelompok, agar siswa dengan sendiri dapat merancang perencanaan kooperatif.

\section{KESIMPULAN DAN SARAN Kesimpulan}

yang diperoleh maka dapat disimpulkan bahwa penggunaan model pembelajaran kooperatif tipe GI pada materi pokok suhu dan kalor di kelas X semester II SMAN 9 Medan T.P. 2015/2016 secara signifikan lebih berpengaruh dalam meningkatkan hasil belajar siswa.

\section{Saran}

Saran yang dapat peneliti ajukan bagi peneliti selanjutnya yang ingin meneliti tentang model pembelajaran kooperatif tipe GI adalah sebagai berikut: (1) agar membimbing siswa dalam pemilihan sub topik sehingga siswa mampu memilih sub topik pilihan yang tidak menyimpang dari materi pembelajaran. (2) Agar mengarahkan siswa dalam membagi tugas dari setiap anggota kelompok, supaya siswa dengan sendiri dapat merancang perencanaan kooperatif.

\section{DAFTAR PUSTAKA}

Arends, R., (2008), Learning to Teach, Pustaka pelajar, Yogyakarta

Harahap, R. dan Turnip, B., (2014), Pengaruh Model Pembelajaran Kooperatif Tipe GI Berbantu Media Flash Terhadap Hasil Belajar Fisika Siswa SMA, Jurnal Inovasi Pembelajaran Fisika (INPAFI), Vol. 2 (3) :156-163

Mudyahardjo, R., (2010), Filsafat Ilmu Pendidikan, Rosda, Bandung

Sakinah, F. dan Purwanto, (2014), Pengaruh Model Pembelajaran Kooperatif Tipe GI terhadap Hasil Belajar Siswa pada Materi Pokok Suhu dan Kalor Kelas $\mathrm{X}$ SMA Negeri I Perbaungan, Jurnal INPAFI, Vol. 2 (3) :84-88

Sani, R., (2014), Inovasi Pembelajaran, Bumi Aksara, Jakarta

Sharan, Y. and Sharan S., (1990), Group Investigation Expands Cooperative Learning, Educational Leadership, Israel 
Simanjuntak, S. dan Simanjuntak, M., (2014), Pengaruh Model Pembelajaran Kooperatif Tipe GI (GI) Berbantuan Media Komputer terhadap Hasil Belajar Siswa pada Materi Pokok Listrik Dinamis di Kelas X Semester II SMA Negeri 10 Medan T.A. 2013/2014, Jurnal INPAFI, Vol. 2 (4) :97-104

Slavin, R., (2005), Cooperative Learning: Teori Riset dan Praktik, Nusa Media, Bandung

Sudjana, (2005), Metoda Statistika, Tarsito, Bandung

Yasemin, Kemal, Ataman, dan Umit, (2010), The Effect of Two Cooperative Learning Strategies on the Teaching and Learning of the Topics of Chemical Kinetics, Journal of Turkish Science Education, Vol. 7 (2) :52-65 